\title{
Advanced heart block aggravated by carbamazepine
}

\author{
B. Beermann, O. Edhag, and H. Vallin \\ From the Department of Medicine, Serafimerlasarettet, Stockholm, Sweden
}

\begin{abstract}
This report presents a serious adverse reaction to the anticonvulsant compound carbamazepine. A woman was admitted to hospital for recurrent attacks of syncope. She suffered from atrioventricular block of the Mobitz type II. Carbamazepine suppressed the conduction in her already defective Purkinje fibres and induced ventricular stand-still with subsequent Adams-Stokes attacks.
\end{abstract}

Several drugs, used for purposes other than for cardiac disease, have been shown to have profound actions on the heart. Among these compounds, the anticonvulsant drug diphenylhydantoin has become an important antiarrhythmic agent with minor effects on atrioventricular conduction (Caracta et al., 1973). We have recently observed that carbamazepine, another anticonvulsant drug, has disturbing effects on His-Purkinje conduction.

The aim of this paper is to report a patient in whom carbamazepine induced complete heart block with subsequent Adams-Stokes attacks.

\section{Case report}

The patient was a 66-year-old woman. She had a cholecystectomy at the age of $3 \mathrm{I}$ years. For six years she had symptoms of slight heart failure and was intermittently treated with digoxin and frusemide. Chest $x$ ray, three years earlier, showed slight enlargement of her heart, confined mainly to the left ventricle. Her electrocardiogram at that time showed sinus rhythm with a PR interval of $0.20 \mathrm{~s}$ and left anterior fascicular block.

For three years the patient had suffered from rightsided trigeminal neuralgia for which she had been prescribed carbamazepine in a dosage of 200 to $400 \mathrm{mg}$ twice or three times daily. This medication gave complete relief of her pain.

Six months before admission to hospital her doctor observed bradycardia, 40 to 50 beats/min and withdrew digoxin. No electrocardiographic record was made. Some weeks later, the patient had a brief syncopal attack. At that time, she had been taking greater amounts of carbamazepine than usual because of increasing neuralgia. Despite the syncope, the patient did not contact any doctor. During the 3 months before her admission into hospital the patient had more or less continuous bradycardia, vertigo, and pronounced dyspnoea.
Ten days before admission the patient was examined by a private practitioner who diagnosed heart failure as well as bradycardia, 40 beats $/ \mathrm{min}$. She was prescribed the cardiac glycoside proscillaridin in a dosage of $0.25 \mathrm{mg}$ four times daily and atropine $0.5 \mathrm{mg}$ three times daily. After that change in medication her dyspnoea and vertigo increased. One day before admission to hospital the patient had another syncopal attack and was, at that time, unconscious for approximately ro minutes. During that day she had taken high doses of carbamazepine but did not remember how many tablets. She was referred to Serafimerlasarettet.

Physical examination in hospital revealed bradycardia with a frequency of $40 / \mathrm{min}$, but no other abnormality was detected. Laboratory examination demonstrated slight anaemia; $\mathrm{Hb}$ Ir.8 g/100 ml. Electrolytes $\left(\mathrm{Na}^{+}\right.$, $\mathrm{K}^{+}, \mathrm{Cl}^{-}, \mathrm{HCO}_{3}^{-}, \mathrm{Ca}^{++}$) S-GOT, S-GPT, and LDH were within normal ranges, as was serum creatinine and bilirubin. Electrocardiogram showed 2-3:I atrioventricular block of the Mobitz type 2 and left anterior fascicular block. Chest $x$-ray was unchanged from that of three years previously and showed slight cardiac enlargement. The patient was prescribed frusemide $40 \mathrm{mg}$ daily, potassium chloride $0.75 \mathrm{~g}$ t.d.s., and carbamazepine $200 \mathrm{mg}$ q.d.s. Proscillaridin and atropine were withdrawn. Four days after admission to hospital the patient had a syncopal attack during which she was pulseless. She recovered after some minutes. The electrocardiogram after recovery showed an unchanged picture, with 2-3:I atrioventricular block.

Transvenous pacemaker stimulation was initiated. The initial stimulation threshold was $0.5 \mathrm{~V}(0.4 \mathrm{~mA})$. The patient's trigeminal neuralgia got worse and the dose of carbamazepine was increased to $400 \mathrm{mg}$ three times daily. During threshold measurements on two subsequent days the electrocardiographic registrations showed regular atrial but no ventricular escape rhythm during an interval of up to $10.5 \mathrm{sec}$. On the suspicion that carbamazepine had induced the block and suppressed 


\section{Without carbamazepine}

\section{0mg carbamazepine 3 times daily}

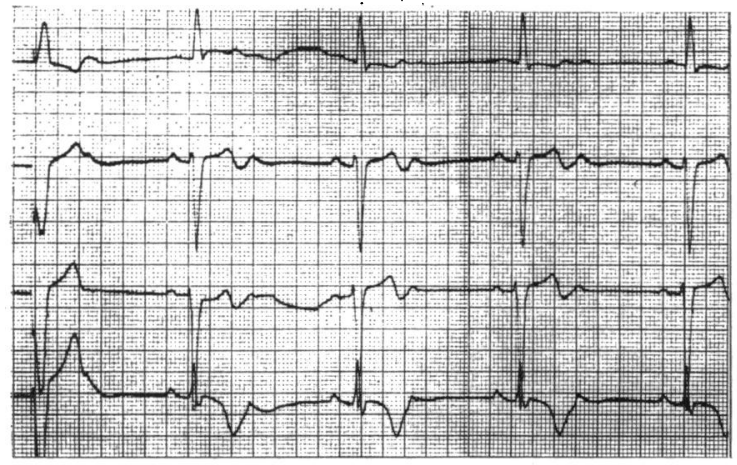

$a$

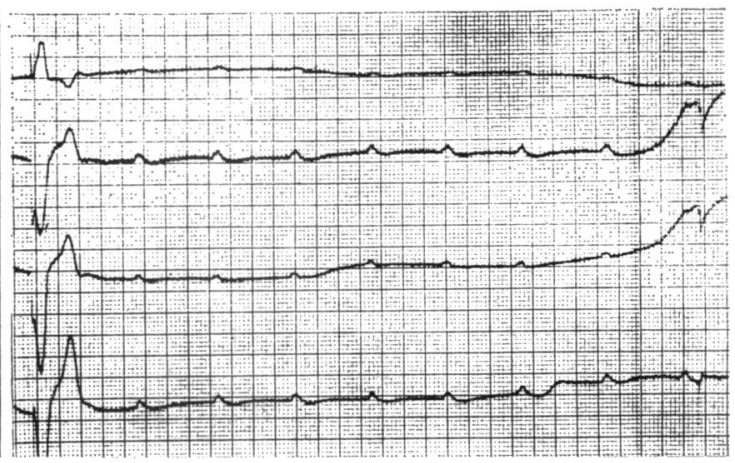

$b$

FIG. I a) Electrocardiogram registered after interruption of pacemaker stimulation. No carbamazepine: leads $I, I I, I I I$, and CR. Paper speed $50 \mathrm{~mm} / \mathrm{s}$. b) Electrocardiogram registered after interruption of pacemaker stimulation. Carbamazepine $400 \mathrm{mg}$ three times daily: leads $I, I I, I I I$, and CR. Paper speed $50 \mathrm{~mm} / \mathrm{s}$.

the idioventricular activity, the drug was withdrawn. Two days later the patient had 2: I atrioventricular block of the Mobitz type 2 (Fig. ra). His bundle electrogram indicated normal $\mathrm{AH}$ conduction and an intermittent block located distal to the bundle of His (Fig. 2a). The patient was given $400 \mathrm{mg}$ carbamazepine orally. Electrocardiogram was registered one hour later and showed 3-4: I atrioventricular block of Mobitz type 2. Represcription of $400 \mathrm{mg}$ carbamazepine 3 times daily, again induced complete heart block. Atrial but no ventricular activity was seen (Fig. Ib). His bundle electrogram still showed normal AH conduction (Fig. 2b). Thus, the block was induced distal to the bundle of His. The drug was withdrawn and the block reverted to $2:$ I atrioventricular block. Carbamazepine was regarded as a dangerous compound for the patient in the event of trouble with the pacemaker system and therefore the patient was given diphenylhydantoin $0.1 \mathrm{~g}$ three times daily. This drug had a good effect on her trigeminal neuralgia and no negative effects on her atrioventricular conduction.

The patient was discharged from hospital. On routine check-up one week later, pacemaker dysfunction was observed. Chest $x$-ray revealed that the pacemaker electrode had been dislodged to the superior vena cava. Since her discharge, the patient has not experienced any dizziness nor has she had any syncopal attacks.

\section{Discussion}

This patient fainted during periods when she had a high intake of carbamazepine, suggesting suppressing effects of the drug on the atrioventricular conduction with subsequent Adams-Stokes attacks. However, the patient had used cardiac glycosides at least on one of the occasions, which might have influenced the atrioventricular conduction. The patient mainly had 2:I atrioventricular block of Mobitz type 2 during the hospital stay when she was free of carbamazepine. There were no signs of delayed conduction through the atrioventricular node. The atrioventricular block was located distal to the bundle of His. One hour after oral administration of $400 \mathrm{mg}$ carbamazepine 3-4: I atrioventricular block II was registered. Prescription of the anticonvulsant compound in the dosage of $400 \mathrm{mg}$ three times daily induced complete heart block, with no demonstrable ventricular activity. His bundle electrogram showed that the atrioventricular conduction block was induced in the already injured part of the conduction system.

This case history shows without any reasonable doubt that carbamazepine had negative effects on the patient's atrioventricular conduction. It also seems probable that carbamazepine decreased the ventricular automaticity, as judged by the observation of lack of ventricular activity, when atrioventricular conduction was completely inhibited.

The negative effects on atrioventricular conduction and possibly on ventricular automaticity are in accordance with the findings by Steiner et al. (1970), who studied the electrophysiological effects of carbamazepine on dog hearts. The drug prolonged atrioventricular conduction moderately 
(a) Without carbomazepine

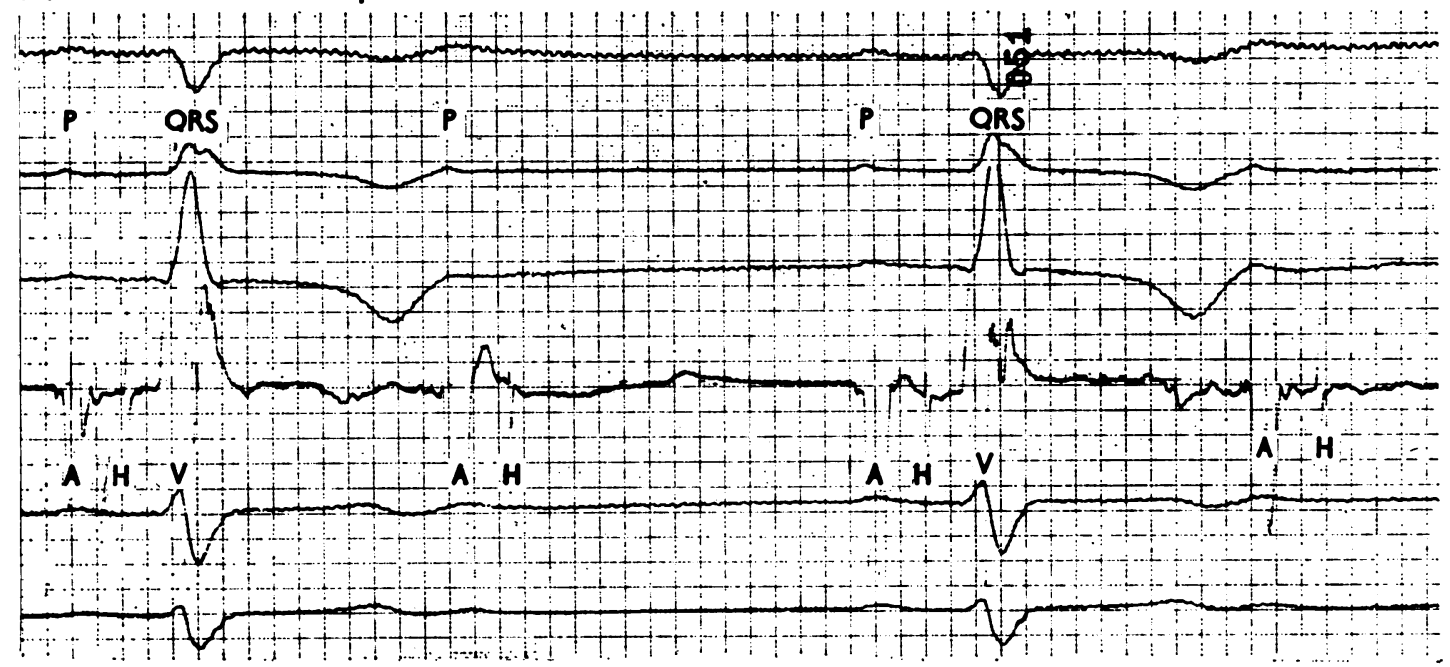

(b) $400 \mathrm{mg}$ carbamazepine 3 times daily

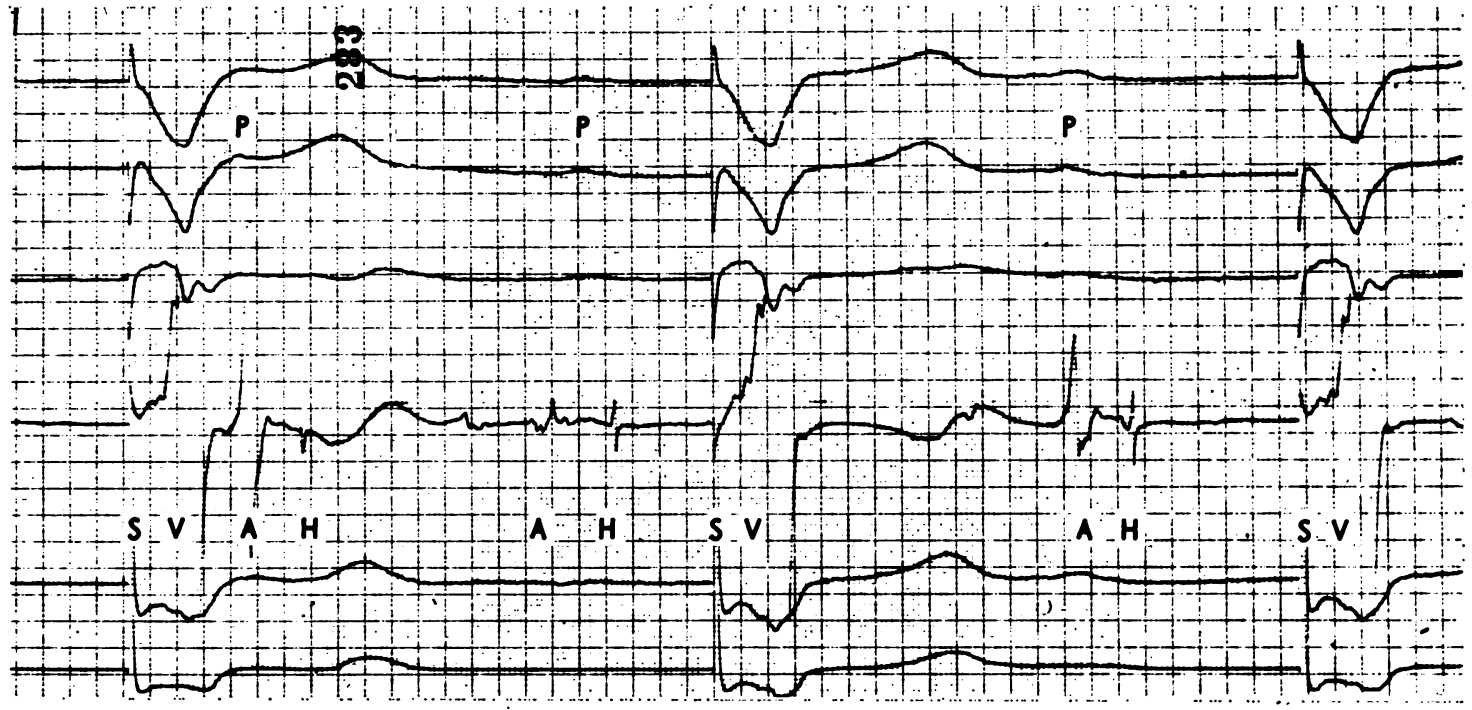

FIG. 2 a) Electrocardiogram and His bundle electrogram. No carbamazepine. A, atrial potential; $H$, His bundle potential; $V$, ventricular potential. Leads $C R_{4} R, C R_{1}, C R_{2}$, His bundle electrogram (HBeg), $C R_{5}$, and $C R_{7}$. Paper speed $100 \mathrm{~mm} / \mathrm{s} .2: \mathrm{I}$ atrioventricular block. $A H$ time $140 \mathrm{~ms}$, HV time $70 \mathrm{~ms}$. b) Electrocardiogram and His bundle electrogram. Carbamazepine $400 \mathrm{mg}$ three times daily. Continuous pacemaker stimulation. S, stimulus artefact; $V$, ventricular potential; $A$, atrial potential; $H$, His bundle potential. Leads $C R_{4} R, C R_{1}, C R_{2}, H B e g, C R_{5}$, and $C R_{7}$. Paper speed $100 \mathrm{~mm} / \mathrm{s}$. Complete atrioventricular block, no spontaneous, only pacemaker-induced ventricular activity. AH time $140 \mathrm{~ms}$. 
in vivo but did not affect the interatrial or the intraventricular conduction. The compound restored sinus rhythm in dogs suffering from ventricular arrhythmias induced by digitalis. In vitro experiments demonstrated depression of phase 4 depolarization and decrease in firing rate of spontaneously active Purkinje fibres.

The present adverse reaction to carbamazepine in man does not appear to have been reported before. The most common side effects of this drug are ataxia, drowsiness, and various allergic reactions (Meyler and Herxheimer, 1972). The lack of reports of cardiac effects after oral administration of carbamazepine to patients indicates that a defective conduction system might be a necessary prerequisite for induction of atrioventricular block by the drug. It is also possible that this effect is more often brought about by therapeutic doses of the drug in patients with latent damage of the conductive system as is the case with digitalis (Edhag, I969).

The present case indicates that carbamazepine should be prescribed with caution to patients with a defective conduction system. To such patients diphenylhydantoin might be prescribed without negative effects on the conduction system as was the case in this patient.

\section{References}

Caracta, A. R., Damato, A. N., Josephson, M. E., Ricciutti, M. A., Gallagher, J. J., and Lau, S. H. (1973). Electrophysiologic properties of diphenylhydantoin. Circulation, 47, 1234.

Edhag, O. (1969). Long-term cardiac pacing. Acta Medica Scandinavica, 186, Suppl. 502.

Meyler, L., and Herxheimer, A. (1972). (Eds.) Side Effects of Drugs, Vol. VII, p. I09. Excerpta Medica Foundation, Amsterdam.

Steiner, C., Wit, A. L., Weiss, M. B., and Damato, A. N. (1970). The antiarrhythmic actions of carbamazepine (Tegretol). Fournal of Pharmacology and Experimental Therapeutics, 173, 323.

Requests for reprints to Dr. B. Beermann, Department of Medicine, Serafimerlasarettet, S-I12 83 Stockholm, Sweden. 